Commentary on The Management of Narcissistic Vulnerability: Three Case Studies Guided by Stephen Mitchell's Integrated Treatment Model

\title{
The Many Complexities in Treating and Studying Narcissism
}

\author{
KENNETH N. LEVY ${ }^{\text {a,b }}$
}

a Department of Psychology, Pennsylvania State University

Correspondence concerning this article should be addressed to Kenneth N. Levy, Department of Psychology, 362

Bruce V. Moore Building, Pennsylvania State University, University Park, PA.

Email: klevy@psu.edu

\begin{abstract}
In this commentary I examine conceptual and methodological issues in Dr. Riordan’s (2012) presentation of three cases treated using Mitchell's integrative model that combines aspects of Kernberg and Kohut's technical stances in the treatment of narcissism. Riordan proposes that Mitchell's integrative model provides a useful blend of Kernberg's focus on defense and Kohut's focus on empathy. He then provides case material to illustrate the benefits of Mitchell's model. In discussing Riordan's paper, I focus on approaches to the case study method and present technical advances in Kernberg's approach that I believe address the concerns articulated by Riordan. These issues are examined in the current context of evidence-based practice.
\end{abstract}

Key words: narcissism; Kernberg; Kohut; Mitchell; Transference Focused Psychotherapy; case study; clinical case study

Dr. Robert Riordan (2012) is to be congratulated for so generously and courageously sharing with us his work with three compelling individuals. It is not easy to share one's clinical work in a professional journal, particularly when one is relatively junior or when presenting work with difficult clients who present with confusing dynamics. In presenting three cases, Dr. Riordan, to our great benefit, provides a platform to deepen our understanding of the subtle dynamics related to narcissistic mental states as they play out in treatment and how one might apply important technical advances. Applying the systematic case presentation approach outlined by Fishman (2005) and others (Peterson, 1991; Dattilio, Edwards, \& Fishman, 2010), Riordan presentation has a number of strengths. These include but are not limited to the use qualitative and quantitative data; use of coherent and recognized theoretical models in both treatment planning and for generating clinical hypotheses; monitoring treatment progress with objective measures; and the derivation of clinical material from recordings. In this commentary, I address the following issues: (1) the goals of the project, including methodological issues in the 
presentation of case material; and (2) the treatment goals with narcissistic patients in light of the tension between evidence based practice and limited evidence.

\section{GOALS OF THE PROJECT}

Riordan states that it is his hope that the clinical material in the three cases presented will provide an integration of Kernberg and Kohut's models by illustrating how technical advances based on Mitchell's integrative model, particularly the concept of narcissistic illusions and the technique of the therapist and patient "playing within the patients illusions." This goal in itself would represent a contribution to the field, but Riordan goes further and adds a number of additional layers of complexity.

First, he imbeds this primary goal in three cases, one characterized by a predominately grandiose presentation, one characterized by a predominately vulnerable presentation, and the third case characterized by significant aspects of both dimensions. Second, in examining three cases, Riordan is implying replication of outcome-an important but often neglected issue in the case study approach. Third, adding further complexity is that Riordan administers two measures, the Narcissistic Personality Inventory (NPI) and the Millon Clinical Multiaxial Inventory-III (MCMI) pre- and post-treatment. Thus there is an implicit, if not explicit goal of linking case material to treatment outcome. Although these goals are laudable, they present certain challenges. Below I articulate some of the challenges I perceive along with some suggestions.

\section{Grandiose and Vulnerable Subtypes}

The distinction between a more overt or grandiose type of narcissism, what Riordan calls “entitled” from a vulnerable covert type, which Riordan refers to as “depleted” has been a conceptually important distinction made by a number of clinical writers over the years (Akhtar \& Thompson, 1982; Bateman, 1998; Britton, 2000; Cooper, 1981; Gabbard, 1989; Masterson, 1981; Rosenfeld, 1987; Wink, 1991). This distinction is supported by a host of factor analytic research that has identified factors corresponding to these dimensions (Dickerson \& Pincus, 2003; Hendin \& Cheek, 1997; Hibbard, 1992; Hibbard \& Bunce, 1995; Rathvon \& Holmstrom, 1996; Rose, 2002; Wink, 1991; 1992). Although not explicitly articulated, the distinction between overt and covert narcissism is important for the consideration of Kernberg and Kohut's approaches because some have suggested that thed differences in their approaches derive from treating different types of narcissistic patients. Kernberg tended to treat the grandiose type and Kohut the vulnerable type. Thus the inclusion of this dimension could have relevance for the question of whether or not Kernberg or Kohut's respective approaches independent of Mitchell's would be sufficient for treating the overt and covert type of patient.

Although a number of contemporary theorists and researchers have emphasized categorical distinctions between overt and covert types among narcissistic individuals, as Riordan points out, aspects of both dimensions to vary degrees can exist within an individual. That is, people need not be categorically grandiose or vulnerable but can vary across these two dimensions. In fact, correlations between these two dimensions tend to be in the .4 range in both clinical and non-clinical samples (Ellison et al., in press; Pincus et al., 2009) indicating that the two dimensions are not orthogonal. Additionally, factor analytic designs do not address whether 
or not there are subtypes of people but rather if there are subtypes of items (or dimensions based on items). Only one study examined the question of subtypes using more relevant cluster analytic procedures and they found a three cluster solution that did not correspond to the grandiosevulnerable distinction (Guiseepee et al., 1995).

Some clinical writers have further extended this idea about the non-exclusivity of these dimensions by stressing that grandiose and vulnerable dimensions may not only co-exists within in an individual but narcissistic dynamics actually involve oscillations of grandiose and vulnerable mental states (Kernberg, 1975/1985; 1971; Levy et al., 2007; 2011; Levy, 2012; Pincus \& Lukowitsky, 2010; Reich, 1960; Ronningstam, 2011). The co-occurrence of these dimensions can clearly be seen in the three cases Riordan presents, despite his classifying two as distinctly entitled and depleted, respectively. Riordan himself even notes that Brian, the depleted case, met criteria for entitlement. Rather than thinking about narcissistic patients as grandiose/entitled or vulnerable/depleted, I think it is useful to assess both grandiose and vulnerable aspects of narcissism in patients and the pattern of oscillation. Mental shifts between grandiose self-states and depressed, defeated, and vulnerable states can provide momentary windows into more reflective, non-defensive spaces. The occurrences of these shifts are difficult to predict. Nonetheless, these are highly valuable opportunities and the therapist must be vigilant for them and seize these moments. However, the idea of classifying patients as predominately one or the other is generally not supported by the data and risks failing to see important aspects of the patients presentation as well as opportunities for intervention.

\section{Links Between Case Material and Treatment Outcome}

With regard to linking the case material to treatment outcome, Riordan reports that all but one of the 17 pre-post tests indicated improvement and that this pattern is significantly nonrandom. I think testing the non-randomness of the pattern of findings is a creative one. One concern, however, is that regardless of the non-randomness of the pattern of symptom reductions, the size of the effect is small and of questionable clinical significance. For example, on the MCMI, the average score goes from 76.33 to 73.00 and two of the patients remain subthreshold for the diagnoses. Another concern is that these 17 subscales are probably highly correlated with each other, particularly within a measure but also between measures (Samuel \& Widiger, 2008). If one was to account for the pattern of intercorrelations based on existing published studies, we might speculate that there are only five or fewer factors between the two measures. If so, even if we stipulated that there were as many as five factors and they all came out indicating improvement, there probably is not be enough power to detect non-randomness.

\section{THE PROBLEM OF TERMS, DEGREES OF FREEDOM, DISENTANGLING CONFOUNDED VARIABLES, AND OF WHAT CONSTITUTES EFFICACY}

\section{Degrees of Freedom}

Riordan's goals of examining different types of patients, different types of treatment, linking the cases to outcomes, and replicating his findings are quite ambitious and he should be 
The Many Complexities in Treating and Studying Narcissism

K.N. Levy

Pragmatic Case Studies in Psychotherapy, http://pcsp.libraries.rutgers.edu

Volume 8, Module 3, Article 3, pp. 216-235, 09-30-12 [copyright by author]

applauded for his interests in addressing them and not shying away from big or complex issues. In doing so, Riordan partly resolves a frequent problem in the case study literature of having too many terms or parameters that result in too many degrees of freedom and not enough power to address the complexity of issues presented (see Campbell, 1975 for an elaboration of this point). Riordan seeks to assess the efficacy of Mitchell's model through the application of Mitchell's integrated treatment model to three long-term psychotherapy cases.

Riordan's design is elegant in that he applies a single treatment model as implemented by the same therapist as applied to three cases. This design keeps constant the therapist, the treatment model, and the pathology and thus provides replication. This design provides a measure of confidence in the finding, however, it does not control for therapist effects or treatment effects as is subtly implied by some of the wording (e.g., use of the word efficacy) or for comparisons between Mitchell's integrative treatment model and that of Kernberg or Kohut's approaches given that techniques from all three approaches are contained in the treatment packaged and therefore confounded. The treatment approached he used combined part of Kernberg's model (defense analysis through more confrontational techniques) with part Kohut's model (allowing mirroring and idealization) and part Mitchell's model (e.g., playing within narcissistic illusions). The fact that these cases involved parts of three treatments, with patients presenting with two dimensions of narcissism, treated by one therapist and assessed at only two data points, confounds too many terms that cannot be disentangled in this otherwise appropriate design for this stage of articulation.

Alternatively, one could use an intensive repeated measures design, in which measures of processes (e.g., session rating form) and pathology (i.e, symptoms or intra and interpersonal problems) are completed by the patient and/or therapist on a session by session or weekly basis. Advances in statistical modeling are among the most important innovations that bear directly on case study methodology (Borckardt, Nash, Murphy, Moore, Shaw, \& O’Neil, 2008; Jones, 1993; Jones et al., 1993; Nash, Borckardt, Abbass, \& Grey, 2011). These approaches, known as person specific approaches are statistically powerful and flexible are very suitable for single-case research and case studies (Molenaar, 2010). The main point I am trying to make here is that one needs to decide what the goals of the case study are design the methodology to fit those goals. Although there are ways of serving multiple aims, one has to be careful so as not to undermine or subvert those aims. It is preferable to have constrain the goals of the study to questions that can be addressed by the design rather that to overreach in the interpretation of the findings.

\section{The Question of Efficacy}

I have concerns with conceptualizing case study design as testing efficacy. In psychotherapy research a distinction is made between efficacy designs and effectiveness designs. I believe that the naming of these designs was initially arbitrary and that these two words are used interchangeably in everyday parlance but are used in treatment research to convey very different information. Efficacy designs are characterized by attention to internal validity have related controls: treatment manuals, trained therapists, adherence and competence ratings, attention to sampling, concerns about caseness, and inclusion and exclusion criteria, randomization with control conditions. Efficacy designs privilege internal over external validity 
The Many Complexities in Treating and Studying Narcissism

K.N. Levy

Pragmatic Case Studies in Psychotherapy, http://pcsp.libraries.rutgers.edu

Volume 8, Module 3, Article 3, pp. 216-235, 09-30-12 [copyright by author]

and tries to control for threats to internal validity through experimental procedures. External validity is controlled for through inferences drawn by comparing treatment completers to intent to treat groups. In contrast, effectiveness research is more concerned with external validity and sacrifices strict controls in favor of looser ones that provide greater ecological validity: patient enter and select treatment on their own accord, few inclusionary and exclusionary criteria, often no control condition and when there is there is no randomization, therapists practice in real world settings in manners consistent with typical practitioners (no manuals, limited supervision), controlling for threats to internal validity statistically. These two types of research address different issues and provide different types of evidence. Although single-case research can provide efficacy data, a case study does not and although a case series (10 or more case studies) could provide effectiveness data in it is tied to outcome data, a case study does not.

In this vain, the case study method should be distinguished from single-case research designs or case series designs (Hilliard, 1993). The single-case method (which can include more than one case) is an objective data intensive design that involves drawing inferences from statistical tests of relationships between independent and dependent variables and can involve experimental manipulation. In some instances, such as when there is experimental manipulation (Kazdin, 2003) or enough assessments to allow examining lagged values, these designs can allow for interpretation of cause and effect relationships (Grange, 1969; Seth, 2007). Aspects of the case study approach can be combined with both single-case and larger group research. Soldz (1990) coined the term research-informed case study to refer to a qualitative individual case study or case studies that have been selected from between-group designs on the basis of quantitative criteria (e.g., based on outcome data in an RCT). Such case studies include objective quantitative data to augment qualitative judgments. Cases in this design are selected based on some systematic criterion or criteria, often in comparison to other cases (e.g., preoccupied attachment vs. dismissive attachment or good outcome vs. poor outcome) and allows for the selection of cases in the context of the controls provided by between-group experimental designs. Studies by Strupp (Strupp, Schacht, Henry, \& Binder, 1992) and Grawe (1992) are exemplars of this approach. Similarly Fishman and colleagues (Dattilio et al., 2010) have advocated for cases studies within a mixed methods paradigm.

Case studies are a rich source of data for ideas and hypothesis generation, can be useful in the context of discovery (Reichenbach, 1938) and for developing therapy technique (see Breuer \& Freud, 1895; Jones, 1924 for examples). Case studies can document rare phenomena, provide falsification, refutation, or counterinstances of ideas considered universal (i.e., Popper, 1934; the black swan metaphor), and can offer support for theories by providing proof of a concept for later testing. They are also useful for providing ideographic data that supports nomotheic data (Allport, 1934; Dattilio, Edwards \& Fishman, 2010; Hislenroth, 2010). But case studies may be best designed and most useful for illustrating concepts, technique and clinical dynamics in teaching and supervision. It is in this realm that I think case reports like Riordan have the most benefit. Providing case material for illustration or teaching is a valuable goal in itself. Tying case material to objective reliable processes and to outcomes is useful for increasing our confidence in clinical observations but only when doing so truly allows for testable inferences or identifying reliable patterns. Although I value and use case studies such as 
The Many Complexities in Treating and Studying Narcissism

K.N. Levy

Pragmatic Case Studies in Psychotherapy, http://pcsp.libraries.rutgers.edu

Volume 8, Module 3, Article 3, pp. 216-235, 09-30-12 [copyright by author]

Riordan's for my own education and as a supervisor and teacher, case studies such as Riordan's cannot provide information about the efficacy of a treatment.

\section{Objective Measurement and the Use of Self-Report Measures for Diagnosis}

Objective measurement of aspects articulated in the qualitative narrative in cases studies provide can increase our confidence the constructs being described. There use also helps us locate the level of difficulty experienced by the patient. Riordan is to be commended for his use of a number of objective measures such as the Personality Assessment Inventory, the Narcissistic Personality Inventory, and the Millon Clinical Multiaxial Inventory-III. However, I would have liked to have seen him use structured interviews to better establish whether or not a patient met criteria for Narcissistic Personality Disorder (NPD). Although Riordan discussed the specific criteria for NPD that was met for each case, it is unclear how the information obtained or what the sources the information was drawn from. Research indicates that clinicians have difficulty accurately diagnosing personality disorders in the absence of structured interviews and that structured interviews provide clinically useful data (Zimmerman \& Mattia, 1999). Structured interviews also insure that onset, duration, scope, threshold, and exclusionary information are gathered and applied to each criterion.

In contrast, Riordan reports using the NPI and MCMI to establish the patient's diagnostic status. Although there is some evidence (Hopwood et al., 2008), at least with BPD, that selfreport data can provide important information in conjunction with structured interviews, the use of self-report assessments as the sole source of diagnostic data is problematic because they tend to "overdiagnose” (McDurmutt \& Zimmerman, 2005) particularly at the beginning of treatment when patients are most distressed. Additionally, self-report generated diagnoses tend to show low associations with diagnoses established by structured interview (Hunt \& Andrews, 1992; Hyler et al., 1990; 1992) and observer ratings (Edell, Joy, \& Yehuda, 1990). Some have suggested the use of multiple-baseline evaluations when using self-report data for study entry to ensure that symptoms are not transient or that observed reductions due to other factors (e.g., statistical regression; Hayes, 1981; Kazdin, 2003) but single administration of self-report measures are inadequate for diagnostic purposes. To Riordan's credit, he uses multiple selfreport measures and DSM criteria to establish diagnosis.

\section{Problems with the Narcissistic Personality Inventory}

The NPI is unequivocally the most utilized measure of self-report measure of narcissism. Since $198577 \%$ of social and personality psychology research conducted on narcissism used the NPI as the only or a primary measure for narcissism (Cain, Pincus, \& Ansell, 2008).

Nevertheless, the NPI is not a clinical measure of narcissism and there is no cut-off score for clinically high narcissism (Foster \& Campbell, 2007). Although Riordan indicates that the NPI is not a diagnostic measure he later reports that Raskin and Terry (1988) found a mean of 15.55 (SD 6.66) and then later suggests that scores above the mean can be used as a clinical cut-off. I don't think that is accurate. Scoring above the mean is not the same as scoring at a clinical level. To illustrate, using a cut-off score of 15.55 almost two thirds of recent college students would be diagnosed with narcissism (Twenge, Konrath, Foster et al., 2008). 
Moreover, the general consensus in the field is that the NPI is limited as a measure for clinical conceptualizations of narcissism (Cain et al., 2008; Miller \& Campbell, 2008; Pincus et al., 2009; Pincus \& Lukowitsky, 2010; Rosenthal \& Hooley, 2010). For instance, most of the subscales of the NPI reliably show weak or even negative correlations with indicators of dysfunction (e.g., Rhodewalt \& Morf, 1995; Watson, 2005) and NPI scores are negatively associated with trait neuroticism and depression, and positively associated with achievement motivation, self-esteem, emotional resilience, and extraversion (Lukowitsky, et al, 2007; Miller \& Campbell, 2008; Rhodewalt \& Morf, 1995; Watson, Little, Sawrie, \& Biderman, 1992). These findings have led some to suggest that the NPI mainly assesses an adaptive form of narcissism (Cain et al., 2008; Pincus et al., 2009; Watson, Trumpeter, O’Leary, Morris, \& Culhane, 2005-2006). Many of the same criticism appear relevant for the MCMI-III Narcissism scale. Consistent with findings from the NPI, Samuel and Widiger (2008) found that the MCMIIII was unrelated to neuroticism, marginally related to antagonism, and highly related to extraversion.

\section{WHAT ARE THE GOALS OF TREATMENT WITH NARCISSISTIC INDIVIDUALS?}

Now I would like to turn to conceptual issue with regard to clinical theorizing and technique. In the beginning of the manuscript, Riordan questions if the ultimate goal in treating narcissistic patients should be the patient's acknowledgement of his or her narcissistic tendencies and renouncement of this orientation. He goes on further to question whether or not full renunciation is realistic should we expect that patients will always struggle with narcissistic personality organization? And, if the restructuring of the patient's personality organization is not a realistic outcome then how do we best help a patient negotiate the world through a narcissistic lens. Later when introducing each of the cases, he explicitly states that one of the main goal for all three patients is for them to "acknowledge" his or "narcissistic orientation" and how it interferes with happiness or productivity or serves the function of keeping them distant from others. I am not exactly sure what acknowledging and renouncing one's narcissistic orientation entails or how it is tied to the issue of personality organization? I think the language of "acknowledge" and "renounce" is problematic. I assume that by "acknowledge” Riordan means to become consciously aware of wishes, desires, concerns, and their dynamics that are typically outside one's awareness and that represent narcissistic concerns. I also assume that by "renounce" he means to become sufficiently invested in making changes in one's life regarding how one thinks, feels, and behaves toward one's self and others, even if it means tolerating painful experiences and giving up some preferred ways of being? I am also not sure of the progression that Riordan goes from questioning the sufficiency or value in acknowledging and renouncing one's narcissistic orientation to accepting that as the treatment goal as indicated in his introduction to each of the three cases. This part was confusing for me. Further, in wondering if changing personality organization is a realistic goal and if not, how do we help our patients proceed through life with narcissism, Riordan is illustrating a common concern that therapist grapple with, namely, what kind of change is possible for our more disturbed patients who suffer not from episodic disorders or disorders based on stimulus-response patterns but more deeply ingrained personality pathology? Riordan is not alone in pondering this issue 
The Many Complexities in Treating and Studying Narcissism

K.N. Levy

Pragmatic Case Studies in Psychotherapy, http://pcsp.libraries.rutgers.edu

Volume 8, Module 3, Article 3, pp. 216-235, 09-30-12 [copyright by author]

especially when it comes to treating patients with NPD whose personality structure can seem so calcified and at the same time both impervious and too brittle to our interventions.

For me, following Kernberg, the goal when treating a patient with narcissism is similar as with most severely disturbed personality disordered patients - the integration of disparate representations of self and others. However, the road to such change is different than with borderline patients. For Kernberg, the goal when treating narcissistic individuals is to eradicate or diminish the patient's pathological grandiose self as well as increase their capacity for relatedness. These achievements occur through the development of increased differentiation and integration of representations of self, others, and affective experience. Whereas for Kohut the goal is to bolster a deficient self-structure, which will lead to less defensiveness and better relatedness.

To achieve his goals, Kernberg advocates a direct approach that brings into awareness disparate representations of self and others using the material that emerges in the session. For Kernberg, these representations are unintegrated as a result of defensive splitting. Through an interpretive process that includes clarifications, confrontations and transference interpretations, the patient becomes more integrated, which results in a more realistic and less grandiose selfstructure. It is important to stress that exploration of narcissistic defenses occurs in context of an empathic understanding of the patient's need for such defenses and the bringing into awareness aspects of experience that the patient is not fully aware in a titrated manner. Confrontations and interpretations need to be calibrated to the patient's phenomenological experience and capacity to integrate them. In this way, these interventions require enormous empathy and tact. Here I am reminded of Jesse Geller's comment that therapeutic tact is the capacity to tell patients something they don't want to hear in a manner in which they can hear it. The integration of these disparate representations is thought to lead to better tolerance of thoughts, feelings, and ultimately achieve better behavioral control.

In contrast to Kernberg's focus on defensiveness and a grandiose self, Kohut stressed, at least initially, facilitating the patient's capacity to bask in the glow of therapist's appreciation of the patient's achievements despite any grandiosity. Relatedly, Kohut advocated encouraging the patient's development of idealizing transference. These processes were seen as essential to allowing normal self development to proceed and to correct for a deficient self-structure.

In trying to understand Kernberg and Kohut's differing positions, Gabbard (2005) proposed the theoretical and clinical differences might stem from having treated different populations of narcissistic patients. Gabbard notes that Kohut's patients tended to be relatively well-functioning outpatients who could afford psychoanalysis. Kohut's patients typically were concerned with vague feelings of emptiness, depression, and problems with relationships. They struggled with self-esteem and were easily slighted or injured by others. In contrast, Kernberg spent his entire career in academic medical centers connected to university hospitals where he based his conceptualization on both inpatients and a broader range of outpatients. Consequently, his clinical descriptions are of patients who are more arrogant, more aggressive, and grandiose. Some of these patients displayed significant antisocial features and most tended to be comorbid with borderline personality disorder. For Kohut NPD was independent from Borderline 
The Many Complexities in Treating and Studying Narcissism

K.N. Levy

Pragmatic Case Studies in Psychotherapy, http://pcsp.libraries.rutgers.edu

Volume 8, Module 3, Article 3, pp. 216-235, 09-30-12 [copyright by author]

Personality Disorder (BPD), with those with BPD having a less cohesive self-structure that made them unsuitable for analysis. In contrast to Kernberg's focus on defensiveness and a grandiose self, for Kohut those with NPD were diagnosable based on showing mirroring and idealizing transferences during the course of treatment. For Kernberg, those with NPD were diagnosable based on his structural interview that assesses personality organization in terms of identity, defenses and social reality testing. In these regards, NPD patients tended to be quite similar to those with BPD.

From a Kernberg approach, the goal of treatment with narcissistic patients is the integration of representations of self and others, which he believes is achieved through an interpretative process that involves clarifications, confrontations, and transference interpretations. However, as indicated earlier, some have suggested that these techniques require some modification from how they are standardly applied in the treatment of BPD, which requires attention to the brittleness of narcissistic patients and their tendency to respond defensively and dropout of treatment when confronted with intolerable affects or thoughts. Thus, the question arises as to how best to address this tension and to proceed technically.

\section{Mitchell Approach as Integration of Kernberg and Kohut}

Riordan suggests that the treatment in each of his cases "required a combination of empathic immersion coupled with the eventual exploration of the patient's narcissistic defenses" (2012, p. 189), which he sees as representing a combination of Kernberg and Kohut's positions. On the one hand, I think that Riordan should be commended for his articulation of this issue and grappling with it so head on. On the other hand, however, I think that this dichotomy between Kohut and empathic immersion on one side and Kernberg defensive exploration on the other is a false dichotomy, both conceptually and in practice. Regardless of theoretical dogma, clinicians practice in the real world, one in which theory has to be fit to real life situations and the complexity of human differences that don't necessarily conform to strong argument theories. Mitchell himself says as much "I strongly suspect that the majority of analysts work in neither of these two sharply contrasting ways, that most of us struggle to find some mid-point, undoubtedly reflective of our own personality and style, between challenging and accepting narcissistic illusions” (1986, p. x). Others have articulated and suggested a similar approach (Gabbard, 2005; Ronningstam, Maltsberg, \& Park, 2007; Wile, 1984). Recent theorizing and modifications made by Diamond, Yeomans, and Stern, colleagues of Kernberg, to Transference-Focused Psychotherapy (TFP) are an explicit articulation of how achieve balance between allowing the patient his or her defenses and gently but systematically addressing those defenses. Other aspects of Kernberg's work that stress empathic immersion include Kernberg's focus on the interplay between internal and external realities and dedication to staying close to the patient's phenomenological experience (but in the context of one's own assessment of a situation). In this regard, Kernberg discusses the importance of using countertransference, which involves an empathic immersion in understanding what the patient might be feeling or what the patient's behavior might evoke in others. Additionally, true empathy involves being aware of all aspects of experience, even those aspects that a patient may not be aware of because they find it intolerable. In being able to bring such material up for discussion, the therapist conveys acceptance and tolerance for part of the patient's experience that they themselves find 
unacceptable and intolerable. The therapist models that such experiences can be talked about and see abstractly rather than concretely. In avoiding such material we implicitly reinforce for our patients implicit beliefs that they are correct in their assessment of the material as being too dangerous to discuss.

Conceptually, it is important to recognize that Kernberg and Kohut emphasized different positions in relation to each other as they were developing their theories. As a result, some of the ideas, on both Kohut and Kernberg's parts may over-emphasize the differences and underappreciate the similarities, even if only they are only subtle ones. This process is not exclusive to Kernberg and Kohut but is a common occurrence in scholarly circles when ideas are first being articulated and established. Subsequent writings will frequently acknowledge and stress the de-emphasized aspects in reaction to contradictory information (i.e., case material, empirical findings) as well as to provide elaboration and nuance. I see Mitchell's integration as part of that process (as well as attempting to establish an independent perspective).

\section{The Question of Dropout in Kernberg's Treatment}

Related, I would like to address the critique that Riordan offers of Kernberg's approach about drop-out. Riordan states that one is unable to treat a patient if they do not come to session, implying that Kernberg's treatment is more likely than Kohut's treatment to lead to drop-out. That critique is unsupported by empirical data in studies using Transference-Focused Psychotherapy (TFP), based on Kernberg's model. In multiple TFP studies-RCTs, pre-post cohort studies, and quasi-experimental studies - conducted both at Cornell and at other institutions with BPD patients, the one-year drop-out rates are comparable to other treatments such Dialectical Behavior Therapy, Mentalization-Based Treatment, and Schema-Focused Therapy, all of which are explicitly more supportive than TFP. Also, the dropout rates in TFP are less than the rates reported in standard, non-specialized treatments. Moreover, there are no differences in drop-out rates as a function of a comorbid narcissism diagnosis or even dimensional narcissism scores. Such concerns about dropout, which may be based on actual experience of some clinicians or they may be unfounded fears, are belied by large $\mathrm{N}$ studies with appropriate controls. My own sense, which is backed up by some evidence, is that patient dropout is most strongly associated with the quality of contract setting (Yeomans et al., 1994; Yeomans, 2006). In my own supervising of graduate students, I believe I can accurately predict drop-out from the quality of the contract setting.

\section{Therapy Process and Mitchell's Model}

On page 156 of his manuscript Riordan states that "Within the context of knowing that the present research will involve only three patients and thus generalization is substantially limited, the qualitative results of the research will be employed to develop tentative guidelines to help other therapists: (a) assess whether Mitchell's integrated model yields benefits different from Kohut's and Kernberg's individual models; (b) to identify those factors in Mitchell's model that appear most efficacious; and (c) to appraise the utility of this author's contributions as an adjunct to Mitchell's integrated treatment model.” 
The Many Complexities in Treating and Studying Narcissism

K.N. Levy

Pragmatic Case Studies in Psychotherapy, http://pcsp.libraries.rutgers.edu

Volume 8, Module 3, Article 3, pp. 216-235, 09-30-12 [copyright by author]

It is clear that all three of the patients Riordan presents were committed to treatment, attached to Riordan as a therapist, and found his work helpful. Riordan was able to skillfully develop a strong therapeutic alliance which allowed him to confront the patient with difficult dynamics and address their defensive structures. Additionally, despite the fact that scores on multiple indicators only decreased slightly, we can see in the characterization of the patient's progress that their lives seemed to have improved in clinically significant ways.

For example, Alex appears to be communicating more openly with his partner. These conversations lead Alex to explicitly realize that he and Zoe shared some goals but that they also had areas on which they differed. He was able to tolerate the differences and recognized and accepted that they would need to calibrate their goals if the relationship would continue. If the relationship did not work out, Alex would most likely not be surprised as opposed to his experience with previous girlfriends. Importantly, with regard to his work life, Alex was able to enjoy his music and the fact that he was part of a locally successful but not commercially successful band. This level of success appeared satisfying to him; and in an integration of his work and love lives, he was able to share his feelings and concerns with Zoe. Brian was also able to better tolerate being in a relationship. He developed the capacity to better enjoy is sex life with his partner Scott. Candace was able to move onto a less prestigious but more satisfying job and appeared less confrontational with others and more desiring of connection. All these changes are important and can have a ripple effect on one's life.

This said, I do not believe that the project design allows the questions posed by Riordan to be sufficiently evaluated. We do not know if the three patients would have done better or worse if treated in either Kernberg's or Kohut's models. Additionally the design does not allow us to evaluate which mechanisms were operative. These questions can only be answered using other designs. Nevertheless, Riordan can theoretically suggest and show through his process examples why the Mitchell's integrative model seemed to be helpful. It is clear that Riordan found Mitchell's conceptualization helpful to him in treating these three patients. He indicates that by adopting this model, he felt less constrained than by what would have been dictated from his understanding of Kernberg or Kohut. Thus, it had heuristic value to him for use with these three patients based on their clinical presentation. Additionally, as a reader one can appreciate the value of the approach Riordan took with these three patients. I would be curious if the same approach would be as useful with more severely disturbed patients who were experiencing more severe problems or were either more entrenched in grandiose or vulnerable presentations or vacillated more quickly between the two.

In a related vein, in a recent article (Levy, 2012), I present a case of a patient who was entrenched in more complex and severe narcissistic dynamics that included drug use, multiple affairs, work failures, family conflict, neglect of children, legal difficulties and so on. In working with this patient, I found a modified TFP approach to be useful. Therein lies the problem with case reports like the ones Riordan and I have published. We can generate clinical data from the consultation room to support our theories' positions and preferred ways of working. Clinical data offer fertile ground for theory building, generating hypotheses to be tested, and for illustrating concepts and dynamics. Clinical data are useful for teaching and supervising. However, clinical data such as the kind I presented (2012) or that Riordan presents here are not 
The Many Complexities in Treating and Studying Narcissism

K.N. Levy

Pragmatic Case Studies in Psychotherapy, http://pcsp.libraries.rutgers.edu

Volume 8, Module 3, Article 3, pp. 216-235, 09-30-12 [copyright by author]

useful for distinguishing good theories from either bad or better ones. Along these lines, in a playful but serious manner that I imagine Riordan would appreciate, Fonagy (2000) eloquently pointed out that: "the proliferation of clinical theories currently in use, is the best evidence that clinical data are more suitable for generating hypotheses than for evaluating them.” (p. 228).

Riordan has however carried out the first step in testing Mitchell's model through provision of an argument and the articulation of clinical innovation. He clearly shows through case material the logic of his thinking and convincingly provides case material. The next step would be to fully articulate the model in a working draft manual that could be used to train therapist and insure adherence to the model (thus internal validity) and to examine additional cases in a case series design. Data from such a design could be used to provide pilot data to obtain funding for a larger $\mathrm{N}$ study.

\section{EVIDENCE BASED PRINCIPLES: A PROPOSAL}

All clinicians faced with treating patients with narcissism face the same dearth of data about how best to proceed. Whereas there is a vast amount of theoretical and clinical writing about how best to conceptualize and treatment individuals with vary degrees of narcissism, there is very little empirical data about how best to proceed in terms of established, articulated treatment packages. Additionally, although, broad reviews of the empirical literature including developmental data, epidemiological data, and experimental data can often help the clinician generate evidence based principles (see Levy et al., 2006; Magnavita, Levy et al., 2010), very little research on data is available on NPD in these realms too. The existing treatment literature is clear that NPD (or even NPD traits) increase the likelihood of dropout and slows symptom change (Campbell, Waller, \& Pistrang, 2009; Ellison, Levy, Cain, \& Pincus, in press; Hilsenroth et al., 1998). Thus, there is clinical utility in accurately identifying NPD or NPD traits. How best to proceed therapeutically is less clear. How best to resolve differences as a result of clinical theory is much less clear.

Because of the dearth of research on narcissism and the level of analysis of the existing literature, there is very little information to resolve the kind of issues clinicians are faced in treating NPD. In the absence of treatment data, case material is our best guide. However, another approach that has some logical and conceptual strength would be to use a modified version of an approach used with a near neighbor disorder such as borderline personality disorder. To do so would be consistent with recent trends in the psychotherapy literature to bootstrap empirically supported treatments for use with disorders that have similar underlying pathology but little existing evidence to guide treatment decisions. Consistent with this approach, a number of clinical researchers have adapted Dialectical Behavior Therapy, which was developed and also shown to be efficacious with BPD patients, for use to other disorders in which there is an impulse control problem such as marital discord, eating disorders, impulse control disorders, substance use disorders, elderly depressed patients, and ADHD (Fruzzetti \& Fruzzetti, 2003; Hesslinger et al., 2002; Lynch et al., 2003; McCann, Ball, \& Ivanoff, 2000; Safer et al., 2001; Telch et al., 2000). Although this approach is not optimal in that the treatment being adapted has not shown efficacy for the disorder, it is a viable approach in the absence of an efficacious treatment. This is especially true when an existing treatment targets a mechanism 
The Many Complexities in Treating and Studying Narcissism

K.N. Levy

Pragmatic Case Studies in Psychotherapy, http://pcsp.libraries.rutgers.edu

Volume 8, Module 3, Article 3, pp. 216-235, 09-30-12 [copyright by author]

that is centrally operative in the disorder for which the treatment will be modified such as DBT for impulse related disorders. This idea of modifying an approach for a near-neighbor disorder has also been applied to anxiety disorders for both cognitive behavior therapy (Barlow, Allen, \& Choate, 2004; Erickson, 2003; Erickson et al, 2007; Norton et al., 2004; Norton, 2008, 2011; Schmidt et al., 2011) and psychodynamic therapy (Busch, Milrod, Singer, \& Aronson, 2011) based treatments. I would suggest that a good candidate treatment to be modified for the treatment of narcissism is Transference Focused Psychotherapy (TFP; Clarkin et al., 2006). TFP is an empirically supported treatment for BPD and this choice would be warranted due to the high level of comorbidity between BPD and NPD as well as the theoretical connection between NPD and BPD (Kernberg, 1975/1985). Additionally, the proposed developmental psychopathology in both BPD and NPD involve integrated representations suggesting that many of the techniques in TFP geared to address this issue in BPD might be useful in the treatment of NPD. Importantly, there is also some preliminary evidence that TFP was uniquely efficacious (Diamond, Yeomans, et al., in press) when compared with DBT and a supportive psychotherapy for a small subset of narcissistic patients from the larger RCT for BPD (Clarkin et al., 2007; Levy et al., 2006).

Along these lines, a group at the Cornell Personality Disorders Institute has been meeting for the last few years to discuss conceptual theory and clinical cases with narcissistic individuals. A number of technical modifications based on the writings of Diamond, Yeomans, Stern and their colleagues (Diamond \& Yeomans, 2008; Diamond, Yeomans, \& Levy, 2011; Diamond, Yeomans, et al., in press; Levy, 2012; Stern, Yeomans, \& Diamond, in press) are suggested to accommodate differences in the borderline and narcissistic pathology. The interested reader is directed to those citations; for the purpose of this commentary I will restrict my comments to modifications in making interpretations that is integrative in a manner consistent with a TFP stance but also with Mitchell and Riordan's recommendations in that it provides an empathic rubric for addressing defenses through interpretation.

The Cornell group has recommended that when making interpretations with narcissistic patients it is important to work outside the transference with the therapist and instead focus on discussing transferences that the patient shows with people outside the therapy setting. A focus on relationships outside the therapeutic dyad often allows narcissistic patients room to explore the contents of their mind in a non-defensive, reflective, and thorough way and may allow for richer elaborations of the patient's internal experience than might be possible when he or she is talking about the same themes in the here-and-now of the treatment relationship. These interpretations can have great immediacy and impact for the patient, and although they have been looked down upon within traditional psychoanalysis, they are consistent with the widening scope model (Bender, 2012). It is also useful when working with this population is to use "analystcentered" rather than patient-centered interpretations (Steiner, 1994; Stern, Yeomans, \& Diamond, in press). This type of interpretation focuses on the patient's experience of the therapist, typically in that moment, and is considered analyst or therapist-focused because it stops short of interpreting the patient's motives to see the therapist in a particular way. Instead, the therapist allows the patient to hold this view of him or her without immediately challenging it, facilitating the examination of the patient's experience of the therapist more deeply and thoroughly. In this way, these extra-transferential and therapist-centered interpretations are 
similar to Mitchell's concept of “playing within the narcissistic illusions.” Although these interventions with a focus on the patient's affective experience are ideally experienced by patients as validating, careful attention is paid so that they are not delivered in a way that reinforces patient distortions or collude with their narcissistic pathology. This is accomplished by maintaining technical neutrality and attending carefully to one's word choices and paralinguistic communication. From this non-judgmental stance, therapist's comment on patients' representation of experience rather than actual reality; over time, therapists introduce an alternate perspective that facilitates a more integrative sense of self and other. For example, a therapist in response to a patient's verbal attack might say: "When I asked about X, you experienced me as attacking you, rather than seeing my question as a sign of my concerned.” The value of providing such validation by holding onto the projection (that it was the therapist who was attacking not the patient) while simultaneously providing an alternative perspective in a gentle and matter of fact manner is that it invites reflection in a non-threatening manner, and provides a base from which to build deeper understandings of the patient's experience. In this way, a therapist-centered interpretation, like extra-transferential work, is preparation for a later transference analysis and transference interpretations. This preparatory or pre-interpretation work helps the patient more readily accept later more confrontational interventions and I believe is consistent with the balance Mitchell acknowledged most therapists are seeking and that Riordan was seeking for himself in the treatments of Alex, Brian, and Zoe.

\section{CONCLUSION}

In summary, I thank Dr. Riordan for sharing his work with us. While I have critically commented on a few issues raised by some of the stated goals and implications of his work that Riordan presents, his case material is rich, complex, and compelling and it is clear that these patients benefited from his work. These cases illustrate a number of important technical advances when working with narcissistic patients, most notably ways in which the therapist can allow the narcissistic patient their narcissistic illusions without colluding with them or reinforcing distorted views but as a method to facilitate the examination of their concerns that allows for exploration, awareness, and integration. In this vein, I suggest that what Mitchell and Riordan call "playing with illusions" is consistent with recent explications of the interpretive process in Transference Focused Psychotherapy (Diamond \& Yeomans, 2005; Diamond et al., in press; Levy, 2012; Stern et al., in press) and can indeed be useful.

\section{REFERENCES}

Akhtar, S., \& Thompson, J. A. (1982). Overview: Narcissistic personality disorder. American Journal of Psychiatry, 139(1), 12-20.

Allport, F. H. (1934). The J-curve hypothesis of conforming behavior. The Journal of Social Psychology, 5(2), 141-184.

Barlow, D. H., Allen, L. B., \& Choate, M. L. (2004). Toward a unified treatment for emotional disorders. Behavior Therapy, 35(2), 205-230. doi:10.1016/S0005-7894(04)80036-4

Bateman, A.W. (1998). Thick- and thin-skinned organisations and enactment in borderline and narcissistic disorders. International Journal of Psycho-Analysis, 79(1), 13-25. 
The Many Complexities in Treating and Studying Narcissism

Bender, D. S. (2012). Mirror, mirror on the wall: Reflecting on narcissism. Journal of Clinical Psychology: In Session, 68(8), 877-885.

Borckardt, J. J., Nash, M. R., Murphy, M. D., Moore, M., Shaw, D., \& O’Neil, P. (2008). Clinical practice as a natural laboratory for psychotherapy research: A guide to case-based timeseries analysis. American Psychologist, 63(2), 77-95.

Breuer, J., \& Freud, S. (1985). Studies on hysteria. Trans. James Strachey. London: Hogarth.

Britton, R. (2000). Hyper-subjectivity and hyper-objectivity in narcissistic disorders. Fort Da, 6, 53-64.

Busch, F. N., Milrod, B. L., Singer, M. B., \& Aronson, A. C. (2011). Manual of panic focused psychodynamic psychotherapy: eXtended range. London, England: Routledge.

Cain, N. M., Pincus, A. L., \& Ansell, E. B. (2008). Narcissism at the crossroads: Phenotypic description of pathological narcissism across clinical theory, social/personality psychology, and psychiatric diagnosis. Clinical Psychiatry Review, 28, 638-656. doi:10.1016/j.cpr.2007.09.006

Campbell, D. T. (1975). Degrees of freedom and the case study. Comparative Political Studies, 8(2), 178.

Campbell, M., Waller, G., \& Pistrang, N. (2009). The Impact of Narcissism on Drop-out From Cognitive-Behavioral Therapy for the Eating Disorders: A Pilot Study. The Journal of Nervous and Mental Disease, 197(4), 278-281. doi:10.1037/a0017733

Clarkin, J.F., Yeomans, F. E., \& Kernberg, O.F. (2006). Psychotherapy for borderline personality: Focusing on object relations. Washington, DC: American Psychiatric.

Clarkin, J. F., Levy, K. N., Lenzenweger, M. F., \& Kernberg, O. F. (2007). Evaluating three treatments for borderline personality disorder: A multiwave study. American Journal of Psychiatry, 164(6), 922-928.

Cooper, A. (1981). Narcissism. In S. Arieti, H. Keith, \& H. Brodie (Eds.), American Handbook of Psychiatry (297-316). New York: Basic Books.

Dattilio, F. M., Edwards, D. J. A., \& Fishman D. B. (2010), Case studies within a mixed methods paradigm: Toward a resolution of the alienation between researcher and practitioner in psychotherapy research. Psychotherapy: Theory, Research, Practice, Training, 47, 427441.

Diamond, D., \& Yeomans, F. E. (2005). Le rôle de la TFP dans le traitement des troubles narcissiques. Santé Mentale au Québec, 33(1), 115-139.

Diamond D \& Yeomans F.E. (2008). Psychopathologies narcissiques et psychotherapie focalisee sur le transfert. (Narcissism, its disorders and the role of transference-focused psychotherapy). Santé Mentale au Québec, XXXIII, 115-139.

Diamond, D., Yeomans, F., \& Levy, K. N. (2011). Psychodynamic psychotherapy for narcissistic personality. In W. K. Campbell \& J. D. Miller (Eds.), The handbook of narcissism and narcissistic personality disorder: Theoretical approaches, empirical findings, and treatments (pp. 423-433). Hoboken, NJ: Wiley.

Diamond, D., Yeomans, F. E., Stern, B. S., Levy, K. N., Hörz, S., \& Delaney, J. C. (in press). Transference focused psychotherapy for Patients with co-morbid narcissistic and borderline personality disorder. Psychoanalytic Inquiry.

DiGiuseppe, R., Robin, M., Szeszko, P. R., \& Primavera, L. H. (1995). Cluster analysis of narcissistic personality disorders on the MCMI-II. Journal of Personality Disorders, 9(4), 304-317. 
The Many Complexities in Treating and Studying Narcissism

Edell, W.S., Joy, S., \& Yehuda, R. (1990). Discordance between self-report and observer-rated psychopathology in borderline patients. Journal of Personality Disorders, 4(4), 381-390.

Ellison, W. D., Levy, K. N., Cain, N. M., \& Pincus, A. L. (in press). The impact of pathological narcissism on psychotherapy utilization, initial symptom severity, and early-treatment symptom change: A naturalistic investigation. Journal of Personality Assessment.

Erickson, D. H. (2003) Group cognitive behavioral therapy for heterogeneous anxiety disorders. Cognitive Behavior Therapy, 32(4), 179-186.

Erickson, D. H., Janeck, A. S., \& Tallman, K. (2007). A cognitive-behavioral group for patients with various anxiety disorders. Psychiatric Services, 58(9), 1205-1211.

Fishman, D. B., \& Messer, S. B. (2005) Case-based studies as a source of unity in applied psychology. In R. J. Sternberg (Ed.), The unification of psychology: Prospect or pipedream? (pp. 37-59). Washington, DC: American Psychological Association.

Fonagy, P. (2000). On the relationship of experimental psychology and psychoanalysis: Commentary by Peter Fonagy. Neuropsychoanalysis, 2, 222-232.

Foster J. D., \& Campbell, W. K. (2007). Are there such things as "narcissists” in social psychology? A taxometric analysis of the narcissistic personality inventory. Personality and Individual Differences, 43(6), 1321-1332.

Fruzzetti, A. E.,\& Fruzzetti, A. R. (2003). Borderline personality disorder. In D. K Snyder \&M. A. Whisman (Eds.), Treating difficult couples: Helping clients with coexisting mental and relationship disorders (pp. 235-260). New York: Guilford Press.

Gabbard, G. O. (1989). Two subtypes of narcissistic personality disorder. Bulletin of the Menninger Clinic, 53(6), 527-532.

Gabbard, G. O. (2005). Mind, brain, and personality disorders. American Journal of Psychiatry, 162(4), 648-655.

Grange, C. W. (1969). Investigating causal relations by econometric models and cross spectral methods. Econometrica, 37(3), 424.

Grawe, K. (1992). Psychotherapieforschung zu Beginn der neunziger Jahre. Psychologische RundFchuu, 43, 132-162.

Hayes, S. C. (1981). Single case experimental design and empirical clinical practice. Journal of Consulting and Clinical Psychology, 49(2), 193-211.

Hesslinger, B., Tebartz van Elst, L., Nyberg, E., Dykierek, P., Richter, H., Berner, M., \& Ebert, D. (2002). Psychotherapy of attention deficit hyperactivity disorder in adults--a pilot study using a structured skills training program. European Archives of Psychiatry and Clinical Neuroscience, 252(4), 177-184. doi:10.1007/s00406-002-0379-0

Hilliard, R. B. (1993). Single-case methodology in psychotherapy process and outcome research. Journal of Counseling and Clinical Psychology, 61(3), 373-380.

Hilsenroth, M. J., Holdwick Jr., D. J., Castlebury, F. D., \& Blais, M. A. (1998). The effects of DSM-IV cluster B personality disorder symptoms on the termination and continuation of psychotherapy. Psychotherapy: Theory, Research, Practice, Training, 35(2), 163. doi:10.1037/h0087845

Hilsenroth, M. J. (2011). In coming editorial: Bigger, purple, pragmatic, and parsimony. Psychotherapy, 48(1), 1-3.

Hopwood, C. J., Morey, L. C., Edelen, M. O., Shea, M. T., Grilo, C. M., Sanislow, C. A., ... Skodol, A. E. (2008). A comparison of interview and self-report methods for the 
The Many Complexities in Treating and Studying Narcissism

K.N. Levy

Pragmatic Case Studies in Psychotherapy, http://pcsp.libraries.rutgers.edu

Volume 8, Module 3, Article 3, pp. 216-235, 09-30-12 [copyright by author]

assessment of borderline personality disorder criteria. Psychological Assessment, 20(1), 81-85.

Hunt, C., \& Andrews, G. (1992). Measuring personality disorder: The use of self-report questionnaires. Journal of Personality Disorders, 6(2), 125-133.

Hyler, S. E., Skodol, A. E., Kellman, H. D., Oldham, J. M., Rosnick, L. (1990). Validity of the personality diagnostic questionnaire-revised: Comparison with two structured interviews. American Journal of Psychiatry, 147(8), 1043-1048.

Hyler, S. E., Skodol, A. E., Oldham, J. M., Kellman, H. D., \& Doidge, N. (1992). Validity of the personality diagnostic questionnaire-revised: A replication in an outpatient sample. Comprehensive Psychiatry, 33(2), 73-77.

Jones, E. E. (1993). Introduction to special section: Single-case research in psychotherapy. Journal of Counseling and Clinical Psychology, 61(3), 371-372.

Jones, E. E., Ghannam, J., Nigg, J. T., \& Dyer, J. F. (1993). A paradigm for single-case research: The time series study of a long-term psychotherapy for depression. Journal of Counseling and Clinical Psychology, 61(3), 381-394.

Kernberg, O. F. (1971). Prognostic considerations regarding borderline personality organization. Journal of the American Psychoanalytic Association, 19, 595-635.

Kernberg, O. F. (1975/1985). Borderline conditions and pathological narcissism. Northvale, NJ: Jason Aronson, Inc.

Kernberg, O. F. (2004). Aggressivity, narcissism, and self-destructiveness in the psychotherapeutic relationship: New developments in the psychopathology and psychotherapy of severe personality disorders. New Haven, CT: Yale University Press.

Kernberg, O. F. (2007). The almost untreatable narcissistic patient. Journal of the American Psychoanalytic Association, 55, 503-539.

Kazdin, A. E. (2003). Psychotherapy for children and adolescents. Annual Review of Psychology, 54, 253-276.

Levy, K.N. (2012). Subtypes, dimensions, levels, and mental states in narcissism and narcissistic personality disorder. Journal of Clinical Psychology, 68, 886-897.

Levy, K. N., Meehan, K. B., Kelly, K. M., Reynoso, J. S., Weber, M., Clarkin, J. F., \& Kernberg, O. F. (2006). Change in attachment patterns and reflective function in a randomized control trial of transference-focused psychotherapy for borderline personality disorder. Journal of Consulting and Clinical Psychology, 74(6), 1027-1040.

Levy, K. N., Reynoso, J. S., Wasserman, R. W., \& Clarkin, J. F. (2007). Narcissistic personality disorder. In W. O’Donohue, K. A. Fowler, \& S. O. Lilienfeld (Eds.), Personality disorders: Toward the DSM-V (pp. 233-277). Thousand Oaks, CA: Sage.

Levy, K. N., Chauhan, P., Clarkin, J. F., Wasserman, R. H., \& Reynoso, J. S. (2009). Narcissistic pathology: Empirical approaches. Psychiatric Annals, 39(4), 203-213.

Levy, K. N., Ellison, W. D., \& Reynoso, J. S. (2011). A historical review of narcissism and narcissistic personality. In W. K. Campbell \& J. D. Miller (Eds.), The handbook of narcissism and narcissistic personality disorder: Theoretical approaches, empirical findings, and treatments (pp. 3-13). Hoboken, NJ: Wiley.

Levy, K. N. (2012), Subtypes, dimensions, levels, and mental states in narcissism and narcissistic personality disorder. Journal of Clinical Psychology, 68(8), 886-897. 
The Many Complexities in Treating and Studying Narcissism

Pragmatic Case Studies in Psychotherapy, http://pcsp.libraries.rutgers.edu

Volume 8, Module 3, Article 3, pp. 216-235, 09-30-12 [copyright by author]

Levy, K. N., \& Clarkin, J. F. (2006). Psychotherapy for patients with borderline personality disorder: Focusing on the mechanisms of change. Journal of Clinical Psychology, 62(4), 405-410.

Lynch, T. R., Morse, J. Q., Mendelson, T., \& Robins, C. J. (2003). Dialectical behavior therapy for depressed older adults: a randomized pilot study. American Journal of Geriatric Psychiatry, 11(1), 33-45.

Lukowitsky, M. R., Roberts, N. R., Lehner, A. N., Pincus, A. L., \& Conroy, D. E. (2007). Differentiating forms of narcissism by achievement related motives and interpersonal problems. Paper presented at the annual meeting of the Society for Interpersonal Theory and Research, Madison, WI.

Magnavita, J. J., Levy, K. N., Critchfield, K. L., \& Lebow, J. L. (2010). Ethical considerations in treatment of personality dysfunction: Using evidence, principles, and clinical judgment. Professional Psychology: Research and Practice, 41(1), 64-74.

Masterson, J. F. (1981). The narcissistic and borderline disorders: An integrated developmental approach. London: Brunner-Routledge.

McCann, R. A., Ball, E. M., \& Ivanoff, A. (2000). DBT with an inpatient forensic population: The CMHIP forensic model. Cognitive and Behavioral Practice, 7(4), 447-456. doi:10.1016/S1077-7229(00)80056-5

McDermut, W., \& Zimmerman, M. (2005) Assessment instruments and standardized evaluation. In J.M. Oldham, A.E. Skodol, \& D.S. Bender [Eds.] American Psychiatric Associations Textbook of Personality Disorders (pp. 89-102). Washington DC: American Psychiatric Publishing.

Miller, J. D., \& Campbell, W. K. (2008). Comparing clinical and social-personality conceptualizations of narcissism. Journal of personality, 76(3), 449-76. doi:10.1111/j.1467-6494.2008.00492.x

Mitchell, S. A. (1986). The wings of Icarus: Illusion and the problem of narcissism. Contemporary Psychoanalysis, 22, 107-132.

Nash, M. R., Borckardt, J. J., Abbasa, A., Gray, E. (2011). How to conduct and statistically analyze case-based time series studies, one patient at a time. Journal of Experimental Psychopathology, 2(2), 139-169.

Norton, P. J., Hayes, S. A., \& Hope, D. A. (2004). Effects of a transdiagnostic group treatment for anxiety on secondary depression. Depression and Anxiety, 20(4), 198-202.

Norton, P. J. (2011). A randomized clinical trial of transdiagnostic cognitive-behavioral treatments for anxiety disorder by comparison to relaxation training. Behavioral Therapy.

Peterson, D. R. (1991). Connection and disconnection of research and practice in the education of professional psychologists. American Psychologist, 46(4), 422-429.

Pincus, A. L., Ansell, E. B., Pimentel, C. A., Cain, N. M., Wright, A. G. C., \& Levy, K. N. (2009). Initial construction and validation of the Pathological Narcissism Inventory. Psychological Assessment, 21(3), 365-379. doi:10.1037/a0016530

Pincus, A. L., \& Lukowitsky, M. R. (2010). Pathological narcissism and narcissistic personality disorder. Annual Review of Clinical Psychology, 6, 421-446. doi:10.1146/annurev.clinpsy.121208.131215

Pincus, A. L., \& Roche, M. J. (2011). Narcissistic grandiosity and narcissistic vulnerability. In W. K. Campbell \& J. D. Miller (Eds.), The handbook of narcissism and narcissistic personality disorder (pp. 31-40). Hoboken, NJ: Wiley. 
The Many Complexities in Treating and Studying Narcissism

K.N. Levy

Pragmatic Case Studies in Psychotherapy, http://pcsp.libraries.rutgers.edu

Volume 8, Module 3, Article 3, pp. 216-235, 09-30-12 [copyright by author]

Popper, K. (1934) Logik der Forschung. Vienna: Springer.

Raimy, V.C. (1950). Introduction. In V. C. Raimy (Ed.), Training in clinical psychology (Boulder Conference). New York: Prentice-Hall.

Raskin, R., \& Terry, H. (1988). A principal-components analysis of the narcissistic personality inventory and further evidence of its construct validity. Journal of Personality and Social Psychology, 54(5), 890-902.

Reich, A. (1960). Pathologic forms of self-esteem regulation. Psychoanalytic Study of the Child, 15, 215-232.

Rhodewalt, F., \& Morf, C. C. (1995). Self and interpersonal correlates of the Narcissistic Personality Inventory: A review and new findings. Journal of Research in Personality, 29(1), 1. Retrieved from http://www.elsevier.com

Riordan, R. W. (2012). The management of narcissistic vulnerability: Three case studies guided by Stephen Mitchell's integrated treatment model. Pragmatic Case Studies in

Psychotherapy, 8(3), Article 1, 150-203. Available: http://hdl.rutgers.edu/1782.1/pcsp_journal

Ronningstam, E. F., \& Maltsberger, J. T. (2007) Narcissistic personality disorder. In: G. O. Gabbard (Ed.), Gabbard's treatments of psychiatric disorders (pp. 791-804). Washington DC: American Psychiatric Publishing.

Ronningstam, E. (2009). Narcissistic personality disorder: Facing DSM-V. Psychiatric Annals, 39(3), 111-121.

Ronningstam, E. (2011). Narcissistic personality disorder in DSM V - In support of retaining a significant diagnosis. Journal of Personality Disorders, 25(2), 248-259.

Rosenfeld, H. (1987). Impasse and interpretation: Therapeutic and anti-therepeutic factors in the psychoanalytic treatment of psychotic, borderline and neurotic patients. New York: Brunner-Routledge.

Rosenthal, S. A., \& Hooley, J. M. (2010). Narcissism assessment in social-personality research: Does the association between narcissism and psychological health result from a confound with self-esteem? Journal of Research in Personality, 44(4), 453-465. doi:10.1016/j.jrp.2010.05.008

Safer, D. L., Telch, C. F., \& Agras, W. S. (2001). Dialectical behavior therapy adapted for bulimia: a case report. The International journal of eating disorders, 30(1), 101-6. doi:10.1002/eat.1059

Samuel, D. B., \& Widiger, T. A. (2008). A meta-analytic review of the relationships between the five-factor model and DSM-IV-TR personality disorders: A facet level analysis. Clinical Psychology Review, 28(8), 1326-1342. doi:doi: 10.1016/j.cpr.2008.07.002

Schmidt, N. B., Buckner, J. D., Pusser, A., Woolaway-Bickel, K., \& Preston, J.L. (2012). Randomized controlled trial of False Safety Behavior Elimination Therapy (F-SET): A unified cognitive behavioral treatment for anxiety psychopathology. Behavior Therapy, 43(3), 518-532.

Seth, A. K. (2008). Casual networks in stimulated neural systems. Cognitive Neurodynamics, 2(1), 49-64.

Soldz, S. (1990). The therapeutic interaction. In R. A. Wells \& V. J. Giannetti (Eds.), Handbook of the brief psychotherapies (pp. 27-53). New York: Plenum Press. 
Steiner. J. (1994). Patient-centered and analyst-centered interpretations: some implications of containment and countertransference. Psychoanalytic Inquiry: A Topical Journal for Mental Health Professionals, 14, 406-422.

Stern, B.L., Yeomans, F., Diamond, D., \& Kernberg, O.F. (In press). In J. Ogrodniczuk, (Ed.). Transference-Focused Psychotherapy (TFP) for Narcissistic Personality Disorder. American Psychiatric Press: Washington, DC.

Strupp, H. H., Schacht, T. E., Henry, W. P., \& Binder, J. L. (1992). Jack M.: A case of premature termination. Psychotherapy: Theory, Research, Practice, Training, 29(2), 191-205.

Telch, C. F., Agras, W. S., \& Linehan, M. M. (2000). Group dialectical behavior therapy for binge-eating disorder: A preliminary, uncontrolled trial. Behavior Therapy, 31(3), 569582. doi:http://dx.doi.org/10.1016/S0005-7894(00)80031-3

Twenge, J. M., Konrath, S., Foster, J. D., Campbell, W. K., \& Bushman, B. J. (2008). Further Evidence of an Increase in Narcissism Among College Students. Journal of Personality, 76(4), 919-928. doi:10.1111/j.1467-6494.2008.00509.x

Watson, D. (2005). Rethinking the mood and anxiety disorders: A quantitative hierarchical model for DSM-V. Journal of Abnormal Psychology, 114(4), 522-536. Retrieved from http://psycnet.apa.orgjournals/abn/114/4/522

Watson, P. J., Little, T., Sawrie, S. M., \& Biderman, M. D. (1992). Measures of the narcissistic personality, Complexity of relationships with self-esteem and empathy. Journal of Personality Disorders, 6(4), 434-449.

Watson, P. J., Trumpeter, N., O’Leary, B. J., Morris, R. J., \& Culhane, S. E. (2005). Narcissism and self-esteem in the presence of imagined others: Supportive versus destructive object representations and the continuum hypothesis. Imagination, Cognition and Personality, 25(3), 253-268. Retrieved from http://psycnet.apa.org/psycinfo/2006-13419-004

Wile, D. B. (1984). Kohut, Kernberg, and accusatory interpretations. Psychotherapy: Theory, Research, Practice, Training, 21(3), 353-364.

Yeomans, F. E., Gutfreund, J., Selzer, M. A., Clarkin, J. F., Hull, J. W., \& Smith, T. E. (1994). Factors related to drop-outs by borderline patients: Treatment contract and therapeutic alliance. Journal of Psychotherapy Practice and Research, 3(1), 16-24.

Yeomans, F. E. (2007). Questions concerning the randomized trial of schema-focused therapy vs transference-focused psychotherapy. Archives of General Psychiatry, 64(5), 609-610.

Zimmerman, M., \& Mattia, J. I. (1999). Differences between clinical and research practices in diagnosing borderline personality disorder. The American Journal of Psychiatry, 156(10), 1570-1574. 